\title{
IAMJ
}

INTERNATIONAL

AYURVEDIC

MEDICAL JOURNAL

\section{GULFA MARMA IN RELATION TO THE MODERN HUMAN ANATOMY}

\author{
Bhumica Bodh $^{1^{*}}$, Sunil Kumar Yadav ${ }^{2}$, Priyanka Verma ${ }^{3}$ \\ ${ }^{1}$ P.G. Scholar, ${ }^{2}$ Associate Professor, ${ }^{3}$ P.G. Scholar \\ Department of Sharir Rachana, National Institute of Ayurveda, Jaipur, Rajasthan, India
}

Corresponding Author: bhumi.rocks9@gmail.Com

https://doi.org/10.46607/iamj1809022021

(Published online: February 2021)

Open Access

(C) International Ayurvedic Medical Journal, India 2021

Article Received: 23/01/2021 - Peer Reviewed: 03/02/2021 - Accepted for Publication: 09/02/2021

(A) Check for updates

\section{ABSTRACT}

Marma is originated from the Sanskrit root word etymologically, 'Mr'- Marne and the term 'Sthana' signifies the location. This jointly signifies the vitality of Marma in the human body. Any kind of injury to these parts of body may cause sensory or functional deformity or severe haemorrhage or even collapse and death instantaneously or lately. The Marma have been included as one of the important chapters in Sharir Sthana of Sushruta Samhita. In which Marma are categorized according to fatality, dimensions, integrity etc. Marma has a common factor as being a seat of Prana or seat of life in Ayurveda literature. Marma therapy focuses on stimulation of these points for activation of Prana factor in management of related disorders. But only described as danger spots of body Marma points have gained a lot of therapeutic importance nowadays. Considering present modern anatomy Marma being a physical entity also should be explored parallelly as it still lacks the adequate and comprehensive western science description. The measurements are given in Anguli Pramana of the person himself. Sushruta has described the anatomical classification of Marma which makes it a little easier to explore them. This will lead to a proper understanding, for better learning and practice of Marma. Gulfa Marma is explored anatomically and in similarity to structure and various other characteristics with modern anatomy.

Keywords: Marma, Prana, Gulfa, Anguli Pramana, Anatomical Aspect 


\section{INTRODUCTION}

The term Marma literary communicates the sense of vital parts of the body. Injuries or mechanical involvements directly affecting the sites of Marma are likely to take away the life of persons concerned or to make him functionless. The knowledge pertaining to location and sites of Marma in the body finds better scope in therapeutic techniques in modern era. The genesis of Marma term is recognized as a mortal spot, vulnerable point, any open or exposed or weak or sensitive part of the body ${ }^{1}$. The ancient literature somehow lacks in the knowledge of advance anatomical background. But the comparison can make the understanding easier and we can know the structures like muscles, vessels, nerves, bones, ligaments lying at the point of Marma which makes the Marma more vulnerable.

The Gulfa Marma is taken into consideration in my article. It is described in text to be situated at the junction of foot (Pada) and (Jangha) leg. It is 2 Angula in size and a type of Sandhi Marma which means it is a joint or junction of structures. Prognostically, it is considered to be in Rujakara Marma that are extreme painful if injured ${ }^{2}$. Injury at particular to Gulfa Marma leads to excessive pain, paralysis of foot and patient will be unable to walk.

\section{Material and Methods}

Textbooks of Ayurveda literature were referred, and other books of Ayurveda specialists were also explored to know there point of views. The modern corelation was done by referring the textbooks of modern human anatomy.

\section{Results}

In Atharva Veda references are available about Gulfa Sandhi.

Acharya Sushruta has mentioned Gulfa Sandhi as Kora Sandhi among the eight types of Sandhi.

In Bhavaprakash, Gulpha Sandhi and Gulfa Marma has been explained in the Purvakanda, Garbha Prakarana Adhyaya.

Acharya Bhela has explained about Gulfa while mentioning the Pratyanga in the $7^{\text {th }}$ chapter of Sharira Sthana. Gulfa is a structure situated at the junction of Pada (foot) and Jangha (leg) and injury to it causes pain, rigidity or limping foot. It is Sandhi Marma in nature, Rujakara in consequence and extends to an area of two Angula. The term is also taken on the name of Gulfa Sandhi ${ }^{3}$.

Ankle joint also called as talo-crural or hock joint. It is formed between the lower ends of bones of leg with upper part of talus. Thus, it is a compound joint involving more than two articular bony areas ${ }^{4}$.

To anatomically approach this joint, define the margins of both extensor retinacula, one flexor retinaculum and both peroneal retinacula. Identify the tendons enclosed in synovial sheaths, nerves and blood vessels passing under them. Displace these structures without removing them. Clean and define the strong medial and lateral ligaments of ankle joints. Also demarcate the thin anterior and posterior parts of the capsule of the joint.

Articular Surfaces- The distal ends of tibia and fibula along with a part of tibio -fibular ligament forms the proximal articular socket. The superior articular facet of talus fits into this socket as a pulley. The medial and lateral articular facets of the talus articulate respectively with the lateral surface of the medial malleolus which is a part of the socket.

Apart from tibia and fibula, the inferior transverse tibio -fibular ligament also participates in the articulation.

Articular Capsule- The fibrous capsule of ankle joint is attached just beyond the margins of the articular surfaces. The capsule is weak anteriorly and posteriorly, but on the medial and lateral side it is reinforced by strong ligaments.

Ligaments- Ligaments play a great role in stability of the joint. These are-

Medial Collateral Ligament- Also known as Deltoid Ligament, due to its delta shape. It is attached proximally to the apical portion of medial malleolus then its anterior fibres pass down to constitute tibio-navicular ligament. The middle fibres attach below form tibiocalcaneal ligament. The posterior fibres pass backwards forming posterior tibiotalar ligament.

Lateral Collateral Ligament- It consists of three different parts. 
- The anterior talofibular ligament, attached proximally to anterior margins of lateral malleolus distally talus.

- Posterior talofibular, attached proximally to malleolar fossa to lateral tubercle of posterior process of talus.

- Calcaneofibular ligaments, which is attached proximally to the apex of lateral malleolus. ${ }^{5}$

Vascular Supply and Lymphatic Drainage -The talocrural joint is supplied by malleolar branches of the Anterior and Posterior Tibial and Fibular arteries. Lymphatic drainage is via vessels accompanying the arteries and via the long and short saphenous veins superficially.

Innervation- The talocrural joint is innervated by branches from the deep fibular, saphenous, sural and tibial nerves (or medial and lateral plantar nerves, depending on the level of division of the tibial nerve). Occasionally, the superficial fibular nerve also supplies the joint.

\section{Relations -}

- Anteriorly, from medial to lateral, are tibialis anterior, extensor hallucis longus, the anterior tibial vessels, deep fibular nerve, extensor digitorum longus and fibularis tertius. Posteromedially from medial to lateral, are tibialis posterior, flexor digitorum longus, the posterior tibial vessels, tibial nerve, flexor hallucis longus.

- In the groove behind the lateral malleolus are the tendons of fibularis longus and brevis. The tendon of fibularis brevis lies anterior to the tendon of fibularis longus at this level.

- The long saphenous vein and saphenous nerve cross the ankle joint medial to the tendon of tibialis anterior and anterior to the medial malleolus, the nerve lying posterior to the vein.

\section{Injuries of Ankle Joint-}

- Ankle sprains, where the ligaments sustain tear are common and very painful. Inversion injury is also a type of ankle sprain. In most ankle sprains, the anterior talofibular ligament is either partially or completely torn resulting in instability of the joint.
- Shearing injuries to the joint causes associated fibular fractures.

- All of the above-mentioned related structures are at risk during surgery on the ankle: the main structures at risk are the neurovascular structures anteriorly and posteromedially. Branches of the superficial fibular nerve are at risk on the anterolateral aspect of the ankle, particularly during ankle arthroscopy ${ }^{6}$.

- Potts fracture -Dislocation of ankle in which, strong medial ligament is pulled, in turn pulling the medial malleolus. The talus moves laterally, shears the lateral malleolus and breaks the fibula. The tibia moves anteriorly, and its distal portion is also sheared off. The distal end of tibia is spoken of as an additional malleolus and the fracture is described as the trimalleolar fracture ${ }^{7}$.

\section{DISCUSSION}

The location of Gulfa as described in the text holds very much similarity with the ankle joint as described in modern anatomy. However, it is still not clearly mentioned in Ayurveda texts whether the Gulfa is located on the medial side or on the lateral side. Likewise, if we see that ankle joint is also formed by joint of talus laterally with tibia and medially with fibula also, the ligaments are also present on both sides. Gulfa is said to be Sandhi Marma, which means a joint or junction; likewise, ankle is a bony joint in structure. Also, many ligaments are organised in a similar point in this site. The anatomical structures like medial malleolus, anterior longus deltoid ligament, posterior ligament, tarsal articulation, anterior talofibular ligament, fibula, posterior talocalcaneal ligament, fibula calcaneal ligament, lateral talocalcaneal ligament are the constituting contents of this Marma. According to the consequence Gulfa is known to be Rujakara Marma, meaning very painful Marma which can be compared with the painful sprains that are common in ankle joint. But, in some latest Ayurveda texts authors have said it to be Vaikalyakara in prognosis maybe due to deformity it causes which leads to pain, rigidity and limping of 
foot as the possible symptoms. These can be co related to Pott's fracture or fractures of ankle joint.

\section{CONCLUSION}

Through the above results and discussions, we can see that Gulfa Marma parallelly accessed with ankle joint is a very vulnerable point. It is very similar in location, structure and prognosis with the ankle joint. However, in some Ayurveda books or Marma books Gulfa is referred to as a Vaikalyakara Marma according to its prognosis of deformity characteristics are similar to that of Vaikalyakara. The anatomical structures like muscles, tendons, ligaments along with the blood vessels and nerves which take part in the formation of joints can be taken as contents of this Marma. Thus, Gulfa Marma can be considered as ankle joint. But, as the ankle joint is made up of both lateral and medial side (malleolus), Gulfa cannot be considered to be on the lateral side alone as described in some Ayurveda texts.

\section{REFERENCES}

1. Dr. L.P. Gupta, Anatomy Of Marma Marma Vyakarana Sarira. Chaukhamba Surbharati Prakashan, Varanasi:2019: Isbn:978-81-9411445-7-1.

2. Kaviraja Ambika Dutt Shastri (2012) Edited With Ayurveda-Tattva-Sandipika,Shushrut Samhita Part 1;ISBN :978-81-89798-19-2

3. Kaviraja Ambika Dutt Shastri (2012) Edited With Ayurveda-Tattva-Sandipika, Shushrut Samhita Part 1, Sharir Sthana Chapter6 Verse 24.;ISBN :978-8189798-19-2

4. Krishna Garg (2010). B D Chaurasia's Human Anatomy-Regional And Applied Dissection And Clinical Ed Fifth, Vol 1; 978-81-239-1863-1.

5. Sudha Seshayyam (2016), Inder Bir Singh's Textbook Of Anatomy, Vol 1, 6thedition; ISBN 978-93-5152963-7.

6. Susan Standring (2008), Gray's Anatomy-The Anatomical Basis Of Clinical Practice 40thedition, ISBN: 978-0-8089-2371-8.

7. Moore, Keith L.; Arthur F. (2006), Clinically Oriented Anatomy, $5^{\text {th }}$ Edition.

\section{Source of Support: Nil \\ Conflict of Interest: None Declared}

How to cite this URL: Bhumica Bodh et al: Gulfa Marma In Relation To The Modern Human Anatomy. International Ayurvedic Medical Journal \{online\} 2021 \{cited February, 2021\} Available from: http://www.iamj.in/posts/images/upload/435_438.pdf 